\title{
Cartographic-Environmental Analysis of the Landscape in Natural Protected Parks for His Management Using GIS. Application to the Natural Parks of the "Las Batuecas-Sierra de Francia” and “Quilamas” (Central System, Spain)
}

\author{
Antonio Miguel Martínez-Graña ${ }^{1}$, Jose Luis Goy ${ }^{1}$, Caridad Zazo ${ }^{2}$ \\ ${ }^{1}$ Geology Department, External Geodynamics Area, Sciences Faculty, University of Salamanca, Salamanca, Spain \\ ${ }^{2}$ Section Geology, National Museum of Natural Sciences, Madrid, Spain \\ Email: amgranna@usal.es
}

Received December 7, 2012; revised January 7, 2013; accepted February 8, 2013

\begin{abstract}
In this work we report a methodological procedure with an integrated physical-perceptual approach that allows units of landscape in protected natural areas to be differentiated. First, indirect methods were applied by means of a mapping procedure, which identified the physical components of major relevance. We then generated maps of natural units, anlyzing the "printed" landscape of a territory. Secondly, we developed direct methods to identify and describe the reresentative elements of the landscape, analyzing the "perceived" landscape. The identification and delimitation of these landscape units with geographical information systems provide detailed maps facilitate the tasks of planning and management. The procedure was validated by means of its application in two protected natural spaces. The treatment used here considers landscape not only as an aesthetic element but also as something "live" elaborating maps that should be of use in land planning and management of natural areas.
\end{abstract}

Keywords: Landscape Cartography; Natural Hazard; Territorial Planning; GIS Techniques; Management Protected Parks

\section{Introduction}

Study of the landscape has developed based on different disciplines—geology, geography, architecture, biologygenerating different definitions, including intangible and tangible values of the same one, constituting a multisensory perception of a system of ecological relations that differentiate a perceptible part and an intangible part: functional and causal factors [1]. The landscape is understood as a set of interrelationships derived from the interaction of its natural components: rocks, water, air, plants, animals, and human beings [2] and their disposition and distribution in the area. Currently, increasing importance is being accorded to the landscape since these environmental values are an important factor in human quality of life, and hence landscape studies may offer a solution to problems generated in the planning of urban development and land management [3-5].

The absence of a clear concept of landscape and the difficulties involved in obtaining manageable information in environmental studies have determined the slow development of its analysis in relation to other natural variables. Correct analysis of the landscape is usually complex since it must bear in mind all the components of the physical medium (geology, geomorphology, vegetation, fauna, soils and human activities) and their interacttions [6,7]. This has elicited a multiplicity of approaches, most of them complementary, to the physical medium, although with a common basis: territorial reality, objective procedures being used in the analysis, and subjective evaluations of the natural quality to estimate the way it is perceived or its beauty $[8,9]$.

Currently, the term "landscape" has evolved beyond previous considerations and is held as a resource on the basis of its aesthetic value generated as an entity derived from the interaction between geology, geomorphology, climate, soils, ecology, vegetation, hydrology, fauna and anthropic activity. A correct analysis of the landscape must necessarily involve study of these components, perceived in different ways, both visual and auditory.

In the last decade, land management has become more flexible and selective, both at the conceptual and meth- 
odological level, and also at the practical level. Thus such that territorial planning establishes a model that is integrated, on the one hand, by structures and territorial systems that increase its internal cohesion (equipment and public services, human settlements, systems of communications and transport). On the other it is constituted by very natural territorial sectors, with special and prominent constitutive characters that require specific measures of protection and management, since they are protected natural spaces in which the maintenance of geobiodiversity can be guaranteed and the environmental conditions of the spaces can be supported. The proposals for the territorial planning of certain structures (infrastructures and urban areas) must be expressed in spatial terms (locations of actions and zoning), and their analysis and diagnosis influences the processes and factors that determine the evolution of the territory and its associated landscape [10-12].

Landscape analysis is useful and effective in territorial planning since it contributes to the correct location and disposition of elements and use of the territory, uncovering the degree of reception and the impact of the use of the physical space. Accordingly, the landscape constitutes a meeting point between the technical, scientific, social and political aspects, allowing civilian participation in proposals of territorial planning (since the term landscape includes the physical spaces where people carry out their daily activities for reasons of work or residence), establishing aims for the conservation of the landscape quality of the territory, as established by the European Landscape Convention.

\section{Background}

Strong but unequal urban and industrial development and that of other human activities in recent decades have influenced landscape quality directly. In 1985, Directive 85/337 regulating Environmental Impact Assessment [13] portrays the landscape as a resource that is subject to rapid deterioration and is difficult to replenish. Thus, in territorial planning it is necessary to attend to its preservation and conservation, and it must be analyzed as another, more independent, factor apart from the abiotic, biotic and socioeconomic factors. Later, in 1992, by means of the European Perspective of Territorial Planning the European Union established the need for an interrelationship between the landscape and territorial planning, favoring as from 1999 an approach towards a balanced and sustainable territorial development across the European Territorial Strategy, as indicated in the Declaration of Lisbon. In Spain, the National Plan of Thematic and Environmental Cartography considers the landscape as a strategic variable, whose mapping defines the landscape as homogeneous units derived from the sum of their components and elements [14].

The European Landscape Convention was convened in Florence in 2008, and the need to determine the effects on the landscape of certain urban development plans and projects, by means of analysis and detailed reports of landscape incidents, was discussed. In Spain the European Landscape Convention was ratified in February 2008 [15]. This promotes measures of protection, management and planning, and the identification and qualification of the territorial landscapes of each region. It also analyzes their characteristics as well as the pressures transforming them, and establishing the aims of landscape quality on the basis of the particular values of each sector, taking into account the participation of the population. In Spain, the drawn-out delay in the implementation of infrastructures during the last decades has led to less development and hence a lower degree of territorial development. Bearing in mind the direct relationship between the degree of use of a territory and its conservation, this implies greater conservation (uncontrolled territories subject to little attention offer a more "natural” image). The low density of the population and its irregular distribution have generated an interrelated mosaic of very diverse landscapes, which determine the territorial perceptual reality of Spain, with a high intrinsic quality unlike the rest of Europe. This is confirmed by the fact that approximately $30 \%$ of the territory is under some degree of national and/or international protection: Natural Protected Spaces, Zones of Special Protection for Birds, and Sites of Community Importance [16,17].

Since 2006, the integration of the landscape in territorial planning has been implemented first by means of strategies and territorial directives that involve treatment of the landscape at general level, defining types and processes that generate them, passing through European, state or autonomous scales. Secondly, it is addressed in plans and planning projects where an analysis of the formal landscape, at regional or local scale, is carried out under the aegis of the procedures of Strategic Environmental Assessment and Evaluation of Environmental Impact. This includes the establishment of maps of landscape units in which these characterize each type of landscape, integrating the components (geological, geomorphologic, botanical, historical and cultural), uses and present activities. In this way our understanding of the landscape and its evolution, especially in natural spaces of interest, is established for application of the European Landscape Convention [18].

At regional level, specific laws have been enacted, such as in Catalonia with Bill 8/2005 concerning the protection, management and planning of the landscape [19]. 
This regulates studies and reports concerning impact and landscape integration, and establishes the need to elaborate landscape catalogues. These offer analyses of descriptive and prospective documents determining the typology of the landscapes of a Community, identifying their values and state of conservation, and proposing quality objectives to be achieved, including the mapping of landscape units, maps of landscape fragility, maps of landscape evaluation (integrating risks and impacts) and maps of landscape quality. This legislation also establishes the drafting of landscape charters as instruments for the reconciliation of strategies between public and private agents with a view to implementing measures of landscape protection, management and planning. It also underscores the need to perform studies addressing landscape integration, determining the consequences of actions and of civil building projects on the landscape. Currently, the landscape, considered as a resource to be conserved and preserved, has a strong impact on the po- pulation, and is a component included within the mapping of the natural heritage as a thematic layer determined by the territorial sectors of greatest landscape quality, and hence those to be protected [8]. In the present work our intention is to improve a methodology aimed at obtaining a mapping of landscape units that will allow us, easily and at low cost, to generate a landscape catalogue for all types of natural spaces.

\section{Methods}

The study of the landscape is linked to the study of natural areas and to that of their evolution and transformation, either as a consequence of natural processes or as a result of human intervention. The landscape, within the context of the perception of the environment, plays an important role in human well-being and quality of life [20]. Accordingly concerns about systematic landscape analyses are steadily increasing. The methodology used here (Figure 1, top) allows Landscape Units to be mapped by

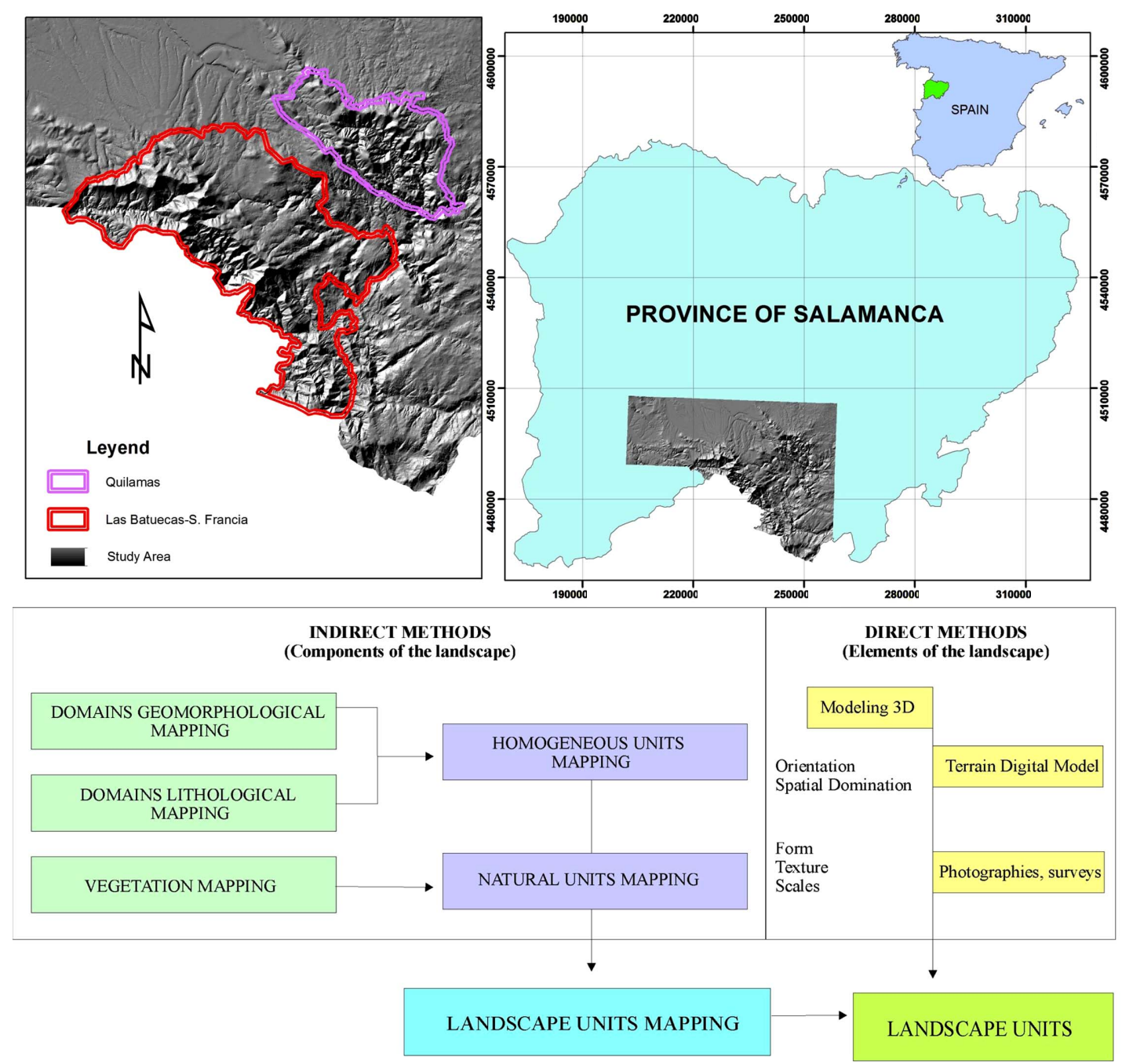

Figure 1. Study area (top) and methodological scheme (down). 
integrating indirect methods that analyze the total landscape, regrouping natural components [21,22], and with direct methods, describing the elements of the "aesthetic" landscape [23,24].

The methodology is confirmed and validated, applying it in two natural spaces protected from the Spanish central mountain system: the Las Batuecas-S. de Francia park and the Quilamas park (Figure 1, lower panel). These natural parks were chosen because they show a direct relationship between landscape quality-visual landscapeand the geological-geomorphologic features, and also feature important areas of geological interest. This value of landscape quality may be reduced owing to anthropic activities, such that landscape analysis is mandatory in planning procedures, both for specific projects (the mining industry and infrastructures (e.g., highways, railroad, housing estates...) and regional strategic projects (housing estates, industrial areas and recreational areas). This analysis is performed from the geological standpoint, using cartographic representation techniques of the natural components, together with aspects from direct observation of the terrain as a new approach for the physicalperceptual analysis of the territory.

To perform the landscape analysis, we divided the territory spatially into landscape units, constructing an ordered and coherent aggregation of the elementary components of each sector, which were classified, re-classified, valued numerically, and then mapped. The landscape unit is a structurally, functionally or visually coherent territorial area subject, partly or totally, to different regimes of protection, management and planning.
In the first phase, we applied indirect objective and quantitative methods based on the evaluation of the constituent components of the landscape, determining the natural units, and their value was calculated from a few weighting coefficients. This was the theoretical valuation of the content of the "image" of a territory. The abiotic factors-geomorphology and lithology-are the most representative and characteristic components of the landscape in the Protected Natural Parks of Las BatuecasSierra de Francia and Quilamas [25]. This method allowed us to identify the landscapes typical of the study sector on the basis of their characteristics and cartographic distribution through the components and elements of the environment. Thus, we obtained a functional methodology for the elaboration of a mapping of units of landscape on the basis of natural homogeneous units-geomorphology-lithology-vegetation, which should be effective for the territorial planning and assignment of land use. In addition, it allows an inventory and a zoning to be made of the places of major perceptual relevance in order to implement legally approved categories of landscape protection. The geomorphologic component was obtained from the synthesis of the maps of geomorphologic units, obtaining the cartography of geomorphologic domains, which can be re-classified according to their representation in the landscape, becoming simplified in the following domains and with their value perceptual weighted: summits (1), watersheds (1), hillsides (2), fitted fluvial valleys (3), surfaces, glacis and pediments (4), fluvial and tectonic scarps (5) and fluvial terraces and valley floors (6) (Figure 2).

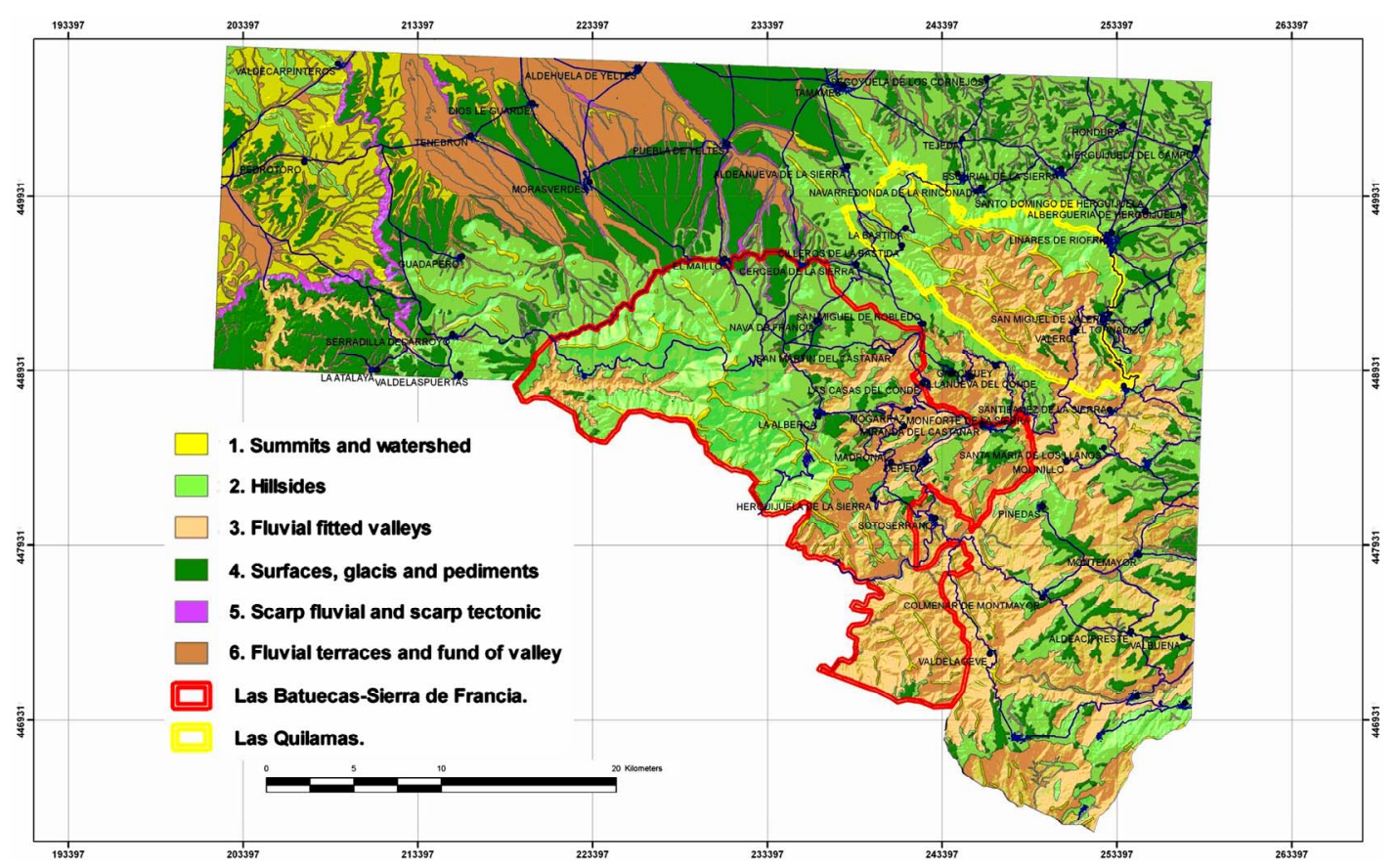

Figure 2. Mapping of geomorphological domains. 
The lithologic component can be established from a synthesis of the geological mapping, extracting the lithological zoning and simplifying the lithological units according to their landscape effect, as: granites (A), quartzites (B), slates, schists and greywacke (C), limestones and dolomites (D), reddish sandstones and brown arkose (E), and conglomerates, gravels, sands and silt (F) (Figure 3).

Integrating the geomorphologic and lithologic maps by means of Geographic Information System-GIS-(ArcGis v.10) techniques, the different units were obtained and simplified, eliminating and/or grouping some on the basis of the following criteria:

1) Very small and dispersed units, which are not perceptually representative and are included in other larger, well-known units.

2) Units that are similar to others, such as for example the groups "2.B" hillsides developed over quartzites, and "2.C" hillsides on slates, would remain integrated within the dominant group "2.C", since at landscape level they behave equally. Likewise, units "3.A", fluvial valleys.

3) The grouping of some units, which are thought to go together owing to their perceptual impact. These units constitute relatively homogeneous portions of the area as regards environmental conditions and landscape components.

4) Elimination of some "mistaken" units generated with the layer of the limits of the study zone.

Finally a map with 14 Homogeneous Units was obtained (Figure 4). Once the Homogeneous Units had been obtained, the third component, which affects the landscape decisively was integrated: i.e., vegetation (Figure 5). To accomplish this, the vegetation map was reclassified for use in the landscape, simplifying the vegetation units in four groups: Arboreal Formations (FA), Sub-shrubby and shrubby Formations (FD), mixed Wooded Formations (FM) and Pastures, Crops and Fallow land $(\mathrm{PaCyB})$. In some sectors there is no vegetation (SV). These vegetation units were grouped as described below: Arboreal Formations (FA): including coniferous (repopulation with pines), leafy evergreen and deciduous (sclerophyllous) forest, dehesa (savannah-like terrain) with holm-oaks, deciduous forest, dehesa of oaks and ashtrees and mixed leafy species (mixed formations of deciduous and sclerophyllous).

Sub-shrubby and shrubby Formations (FD): including all the scrubs, that is both Shrubby Formations (fructicose shrub formation, outcrops with rockrose and heather) and Sub-shrubby Formations (lavender, thymes, brooms, and Genista shrubs) fitted within granite, and "4.C", surfaces on slates and granites, were integrated since they are intermingled over the landscape, thus defining specific singular units. Finally, units "5.C": scarp on slates and "5.E", scarp on conglomerates and sandstones, were

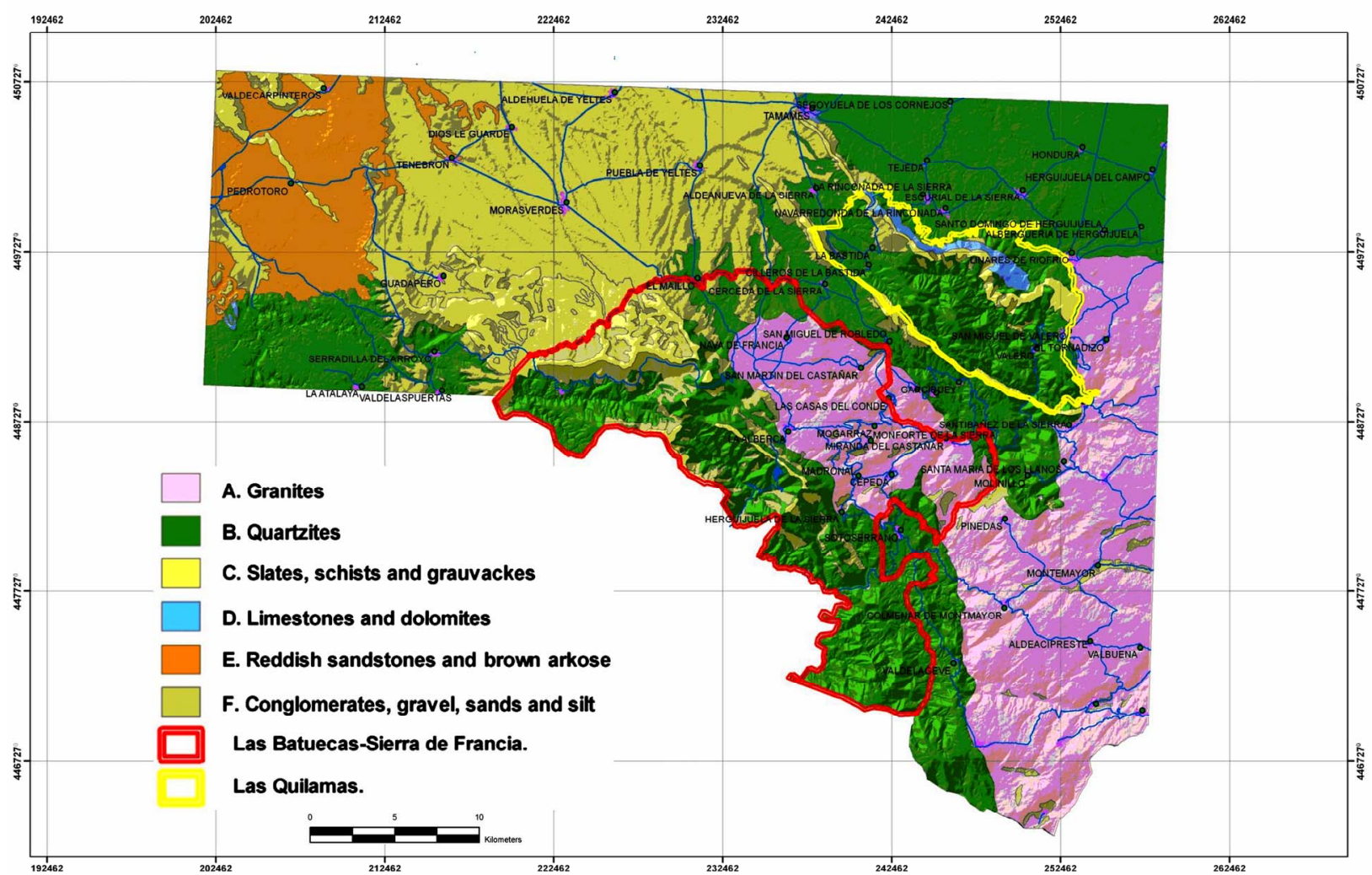

Figure 3. Mapping of lithological domains. 


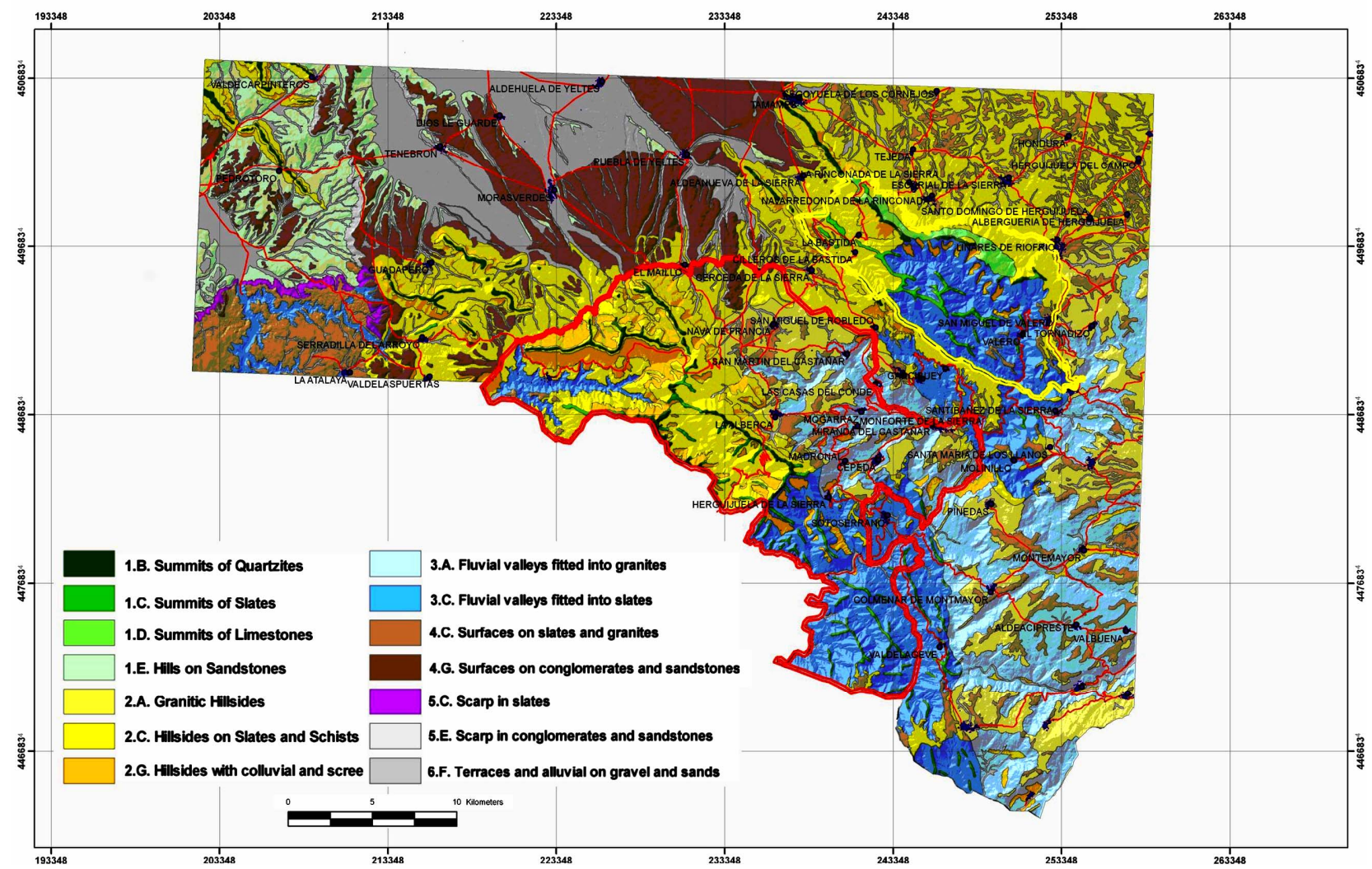

Figure 4. Mapping of homogeneous units.

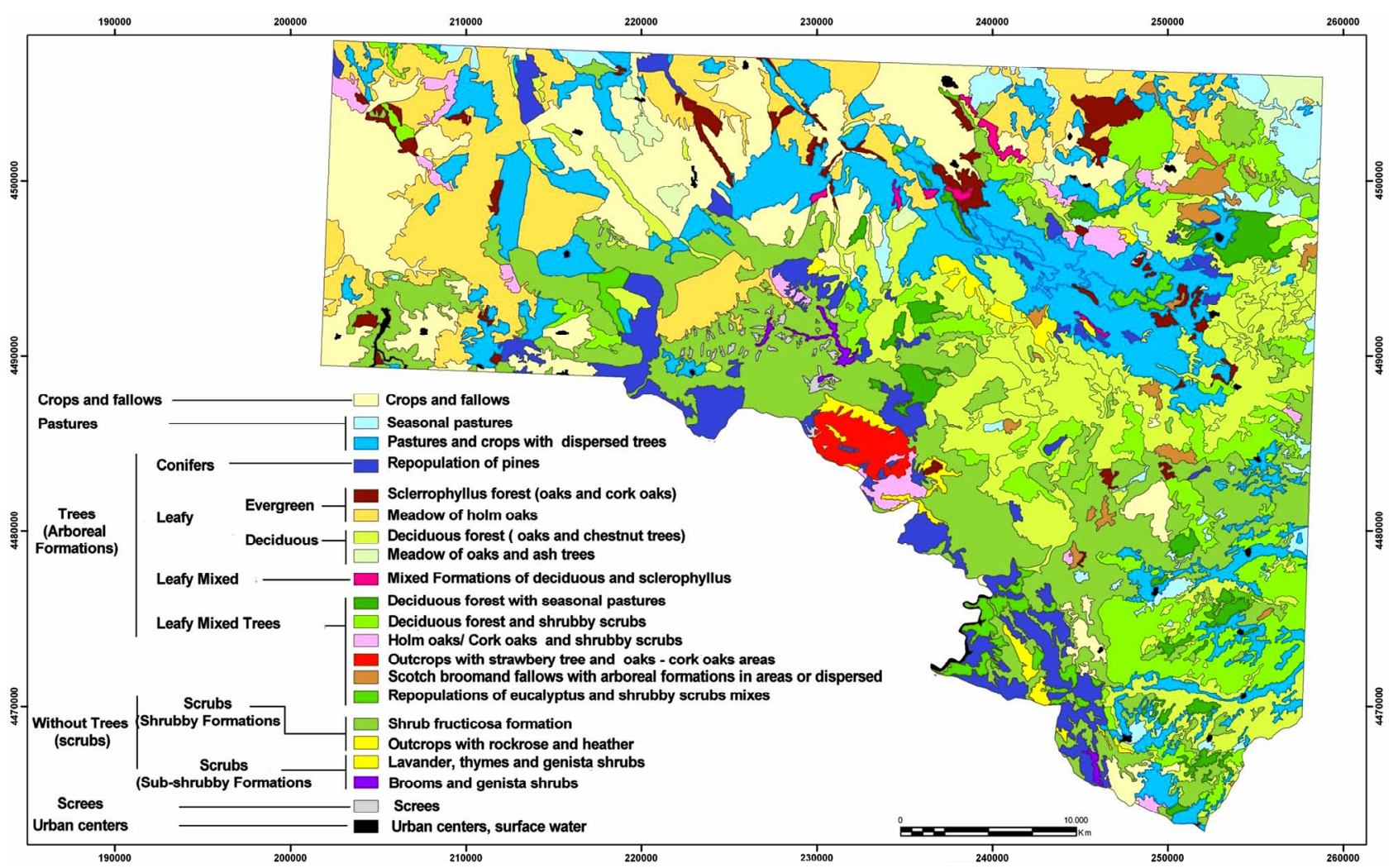

Figure 5. Mapping of vegetation. 
grouped because they affect the landscape, especially the geomorphologic domain, but not the lithological differences.

Mixed Wooded Formations (FM): including a mosaic of deciduous forest with seasonal pastures and shrubby scrubs, deciduous forest with scrubby (sub-shrubby) formations, oak-cork and oak areas, scotch broom and genista shrubs with arboreal formations, either dispersed or in clumps, repopulations of eucalyptus and shrubby scrub mixes.

Pastures, Crops and Fallow Land (PaCyB): including vivacious seasonal pastures and pastures with dispersed arboreal elements. In this unit, we integrated the crops and fallow areas.

Integration of the mapping of homogeneous units and the mapping of the vegetation simplified for the landscape generated cartography of natural units with 21 units, some of them lacking perceptual importance, and others very delimited within each unit. Accordingly, we were analyzing the possible integration of the type and spatial position of the vegetation units in the homogeneous units, obtaining a mapping of natural or environmental units (Figure 6).

The methodological procedure developed prioritizes the groups of landscape units on the basis of geomorphological domains, since they are units that print the spatial configuration of the relief. We also took into ac- count the lithological units in sectors where they had added landscape value, such as high and slope sectors, coinciding with shrubby and sub-shrubby or mixed formations, understanding that in zones with wooded or mixed formations the density and/or wooded stands eliminate the differential colour of the lithological substrate.

Accordingly, and in light of the peculiarities of the study zone, on the slopes we differentiated the lithological unit of the slates, which impose a green-to-dark-grey colour, and the light colour of quarzites. In the summit and ridge domain, Armorican quartzite predominates with respect to the other lithologies (granites, slates...), which is of special relevance, since with their original white crests they stand out on the terrain.

We next addressed the type and disposition of the plant masses, grouping them according to their singularity, the degree from which they stand out from the surroundings according to their height and nature, in different geomorphological domains and in four groups: Wooded formations (FA), Shrubby and sub-shrubby formations (FD), Mixed formations (FM) and in more anthropic units (PaCyB: pastures and crops, fallow land). Once we had reclassified the natural or environmental units, we obtained 11 landscape units that provided the cartography of landscape units (Figure 7).

In the mapping of the landscape units, we observed

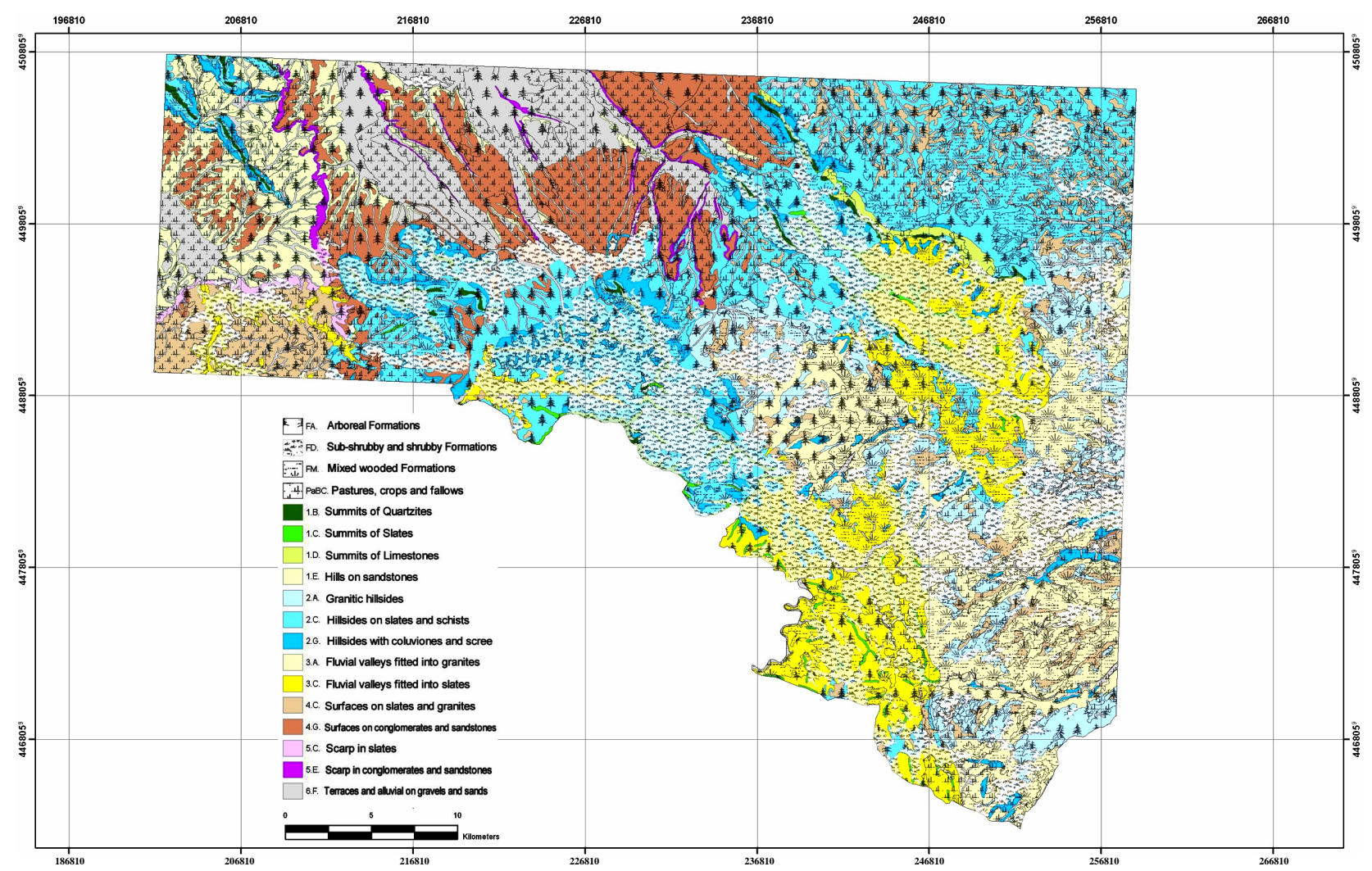

Figure 6. Mapping of natural or environmental units. 


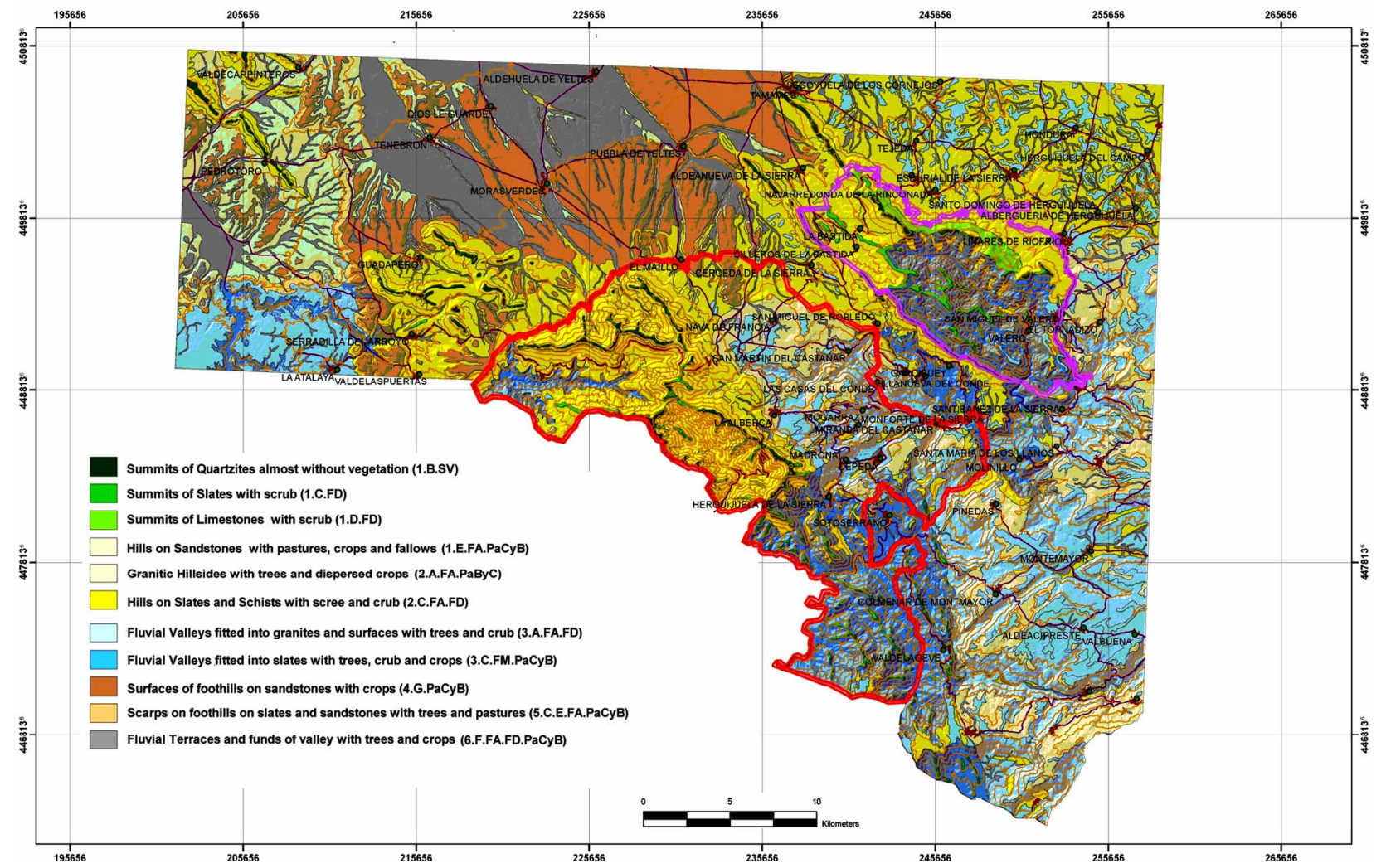

Figure 7. Mapping of landscape units.

that the highest sectors (Unit 1: 1.B.SV, 1.C.FD, 1.D.FD, 1.E.FA.PaCyB, green colours on the map) show the following units: summit (Ridge) sectors without vegetation (SV) covered by colluvials, especially screes, which owing to their disposition and colour stand out perceptually (visually). It is also necessary to mention the hill and hillside sectors with wooded formations (FA) and, to a lesser extent, pastures and croplands-fallow lands (PaCyB) in the western sector. These are not very abundant units although they are representative of the sub-shrubby and shrubby formations of the summits and scarps (El Maillo-Puebla de Yeltes).

The hillsides (Unit 2: 2.A.FA.PaCB, 2.C.FA.FD, yellow on the map) are highly representative domains in the centre of the Natural Area of Las Batuecas-Sierra de Francia and in the NE sector of the study zone, wooded formations being outstanding in the SW sector, with large patches of shrubby and sub-shrubby formations predominating in the rest of the natural park on the hillside of the S sector. In the NE sector there is a predominance of pastures and croplands-fallow land.

The sectors of fitted valleys Unit 3: 3.A.FA.FD, 3.C.FM.PaCyB, in blue), are distributed within the natural parks of the Quilamas and the S and SE parts of Las Batuecas, with a predominance of shrubby and sub-shrubby vegetation (FD), in the between-sierra sectors (Garcibuey, Sequeros), followed by mixed formations (FM) in zones adjacent to the previous ones but of lesser extension in the eastern zone (Fuente de San Esteban, Linares...) and SE (Pinedas, Montemayor del Río...). The units with wooded formations are less well represented and are distributed in the S and SE sector surrounding the river valleys.

The mainly flat surfaces (Unit 4: 4.G.PaCyB, in brown) are found at the periphery of the natural parks, dispersed among the granitic valleys, or are seen in the $\mathrm{N}$ and $\mathrm{E}$ sectors as discontinuous below pasture formations over sediment-filled surfaces ( $\mathrm{N}$ sector) and over erosive surfaces (E sector). The pediment has mixed formations, showing highly dispersed remnants of shrubby and subshrubby formations (FD). Fluvial and tectonic escarpments (Unit 5: 5.C.E.FA.PaCyB, in orange) are important on the right bank of the Yeltes river, the fluvial escarpment that goes from El Maillo to Aldehuela de Yeltes being displaced and retracted, as is the tectonic escarpment, to the NE of the study zone.

Finally, the terraces and valley floors (Unit 6: 6.F. FA.FD.PaCyB, in grey), mainly associated with the river courses of the northern zone of the study area (Tenebrón, Dios le Guarde, Morasverdes...), have wooded formations (FA) in the northern and eastern sectors, and on the valley floors there is a preponderance of riverbank wooded formations and/or repopulated forest.

This systematic identification of the landscape by 
means of indirect methods, from the inventory of the different components forming it, allows easy integration and characterization of the landscape mapping, which is of great use for environmental planning.

In a second phase the landscape analysis was complemented with direct methods [26], describing the different landscapes on the basis of their visual characteristics by direct observation of the terrain and photos taken during the different seasons of the year and then performing a subjective evaluation. We performed an analysis of the visual perception and aesthetics of each sector, without separating their components, such that the landscape would offer a perceived and printed "image" of a territory.

To accomplish this, different direct methods of controlled subjectivity were used, with evaluations by categories. We noted that this method was strongly influenced by the observer, who shows a descriptive attitude conditioned by his/her individual expectations (educational level, age, social status...). With the mapping of homogeneous units we carried out an analysis of the most representative units of the study zone, assessing the areas of singular landscape-touristic interest according to questionnaires concerning the best evaluated components and elements present in the zones, and identified the different landscape components with 3D modeling (Figures 8(a) and (b)) from the Digital Model Terrain on which we implemented different thematic layers (geomorphology, lithology and vegetation). We also used direct methods of representative subjectivity, in which the values were obtained from questionnaires given to population groups, and also from fragments of the terrain by photos, which always give only a limited view of landscapes, then making a description from different observational points of the landscape elements (colour, scale, textures, shapes, lines and spatial distribution) in each perceptual scenario, visual organization of the park (existing visual contrast: between colours and shapes, spatial dominance [23], visual vulnerability and visual absorption capacity (Figures 8(C) and (D)).

Both methods were used in the territorial analyses. Initially, the direct method predominated owing to its ease of application. Currently we are starting to develop indirect methods, in parallel with the advance in IT tools for cartographic treatment, such as geographic information systems (GIS). However, the assessment of a landscape via direct methods (subjective assessment by the observer) does not necessarily have to coincide with the indirect assessment of the quality of that landscape. For example, an arid landscape with certain endemisms may be of high value as regards its specific nature (e.g., biological/geological interest) but, in contrast, may not be particularly attractive to the aesthetic preferences of most people.
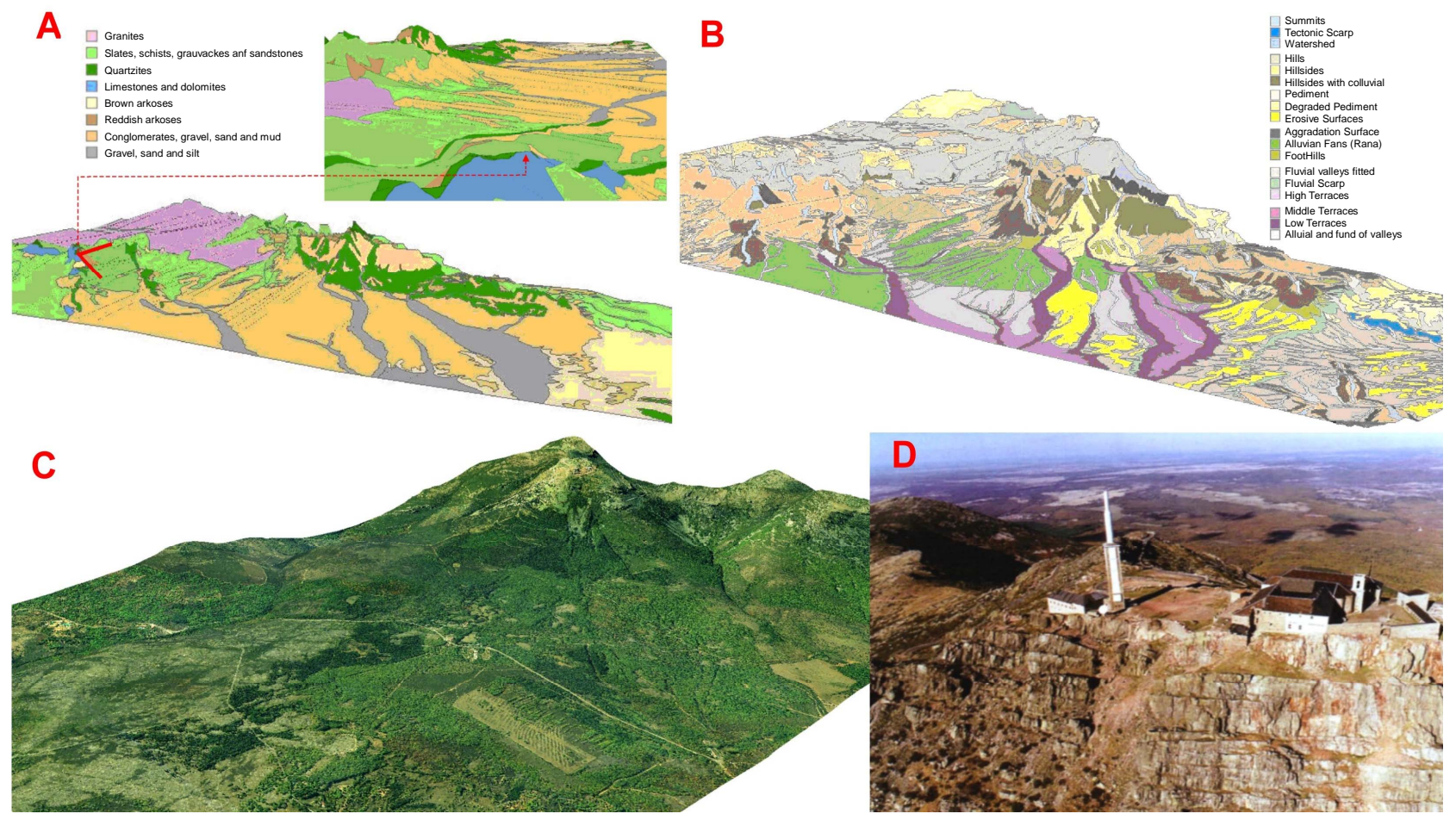

Figure 8. 3D Models showing the spatial distribution of the lithology (A), and of the geomorphological domains (B). Digital Terrain Model of the "Peña de Francia" (C) and dominant lithology in the landscape of the summit of the "Peña de Francia" (D). 


\section{Results}

Analysis of the landscape of the natural parks of Las Batuecas-Sierra de Francia and the Quilamas, the attitudinal and topographic variation, the geobotanical differentiation and the different forms of human activities and life-styles govern the occupation of the territory and allow a landscape differentiation to be made according to the large geomorphological domains that form part of the landscape units, characterized by their natural components and elements, as detailed below.

Saw Landscapes (Units of Landscape: 1.B.SV, 1.C.FD, 1.D.FD, 1.E.FA.PaCyB). The units included in the saw sectors are open, or panoramic, landscapes in which the limitation to sight goes far beyond the point at which elements can be properly recognized. It is possible to note the disposition of the regional relief, with a predominance of horizontal lines, and the sky occupies a large part of the scenic background. These panoramic landscapes are seen from the hills and summits. The quartzite outcrops, which form abrupt walls and steep watersheds, stand out over non-arboreal formations in broad sectors of the upper slopes of the Quilamas and Francia sierras and the surroundings of Guadaperro.

In this sector the landscapes are ordered as a function of their altitude, which in turn determines the climatic conditions and hence the geodynamic processes (screes and slides), the installation of the vegetation and human settlements.

The 1.B.SV landscape unit corresponds to quartzite summits almost completely lacking in vegetation. In these high sectors, there is a predominance of abiotic components since the forest vegetation disappears and is replaced by shrubland and pastures, which are elements of lesser landscape interest than forest. By contrast, the abiotic elements become more abundant and stand out more, with the presence of summits of Armorican quartzite, rocky summits, screes and high slopes featuring little vegetation. These outcrops of quartzite standing out at the top, many of them due to the resistant nature Armorican Ordovician quartzite, display sub-shrubby or shrubby formations.

The above sharp outcrops of quartzite, periglacial morphologies such as detritus left by the snow cover and continuous structures on the summits draw attention to the landscapes featuring such elements in environments relatively close to the observation points (Figure 9(A)). At perceptual level, these sectors offer a panoramic space, with lines of diffuse borders due to periglacial deposits with a medium-sized grain texture in groups. Depending on the vegetation they display important colour contrasts (intense flowering of broom and grasses), especially in spring and autumn. They form zones of singular scientific interest as well as being sectors of considerable co-

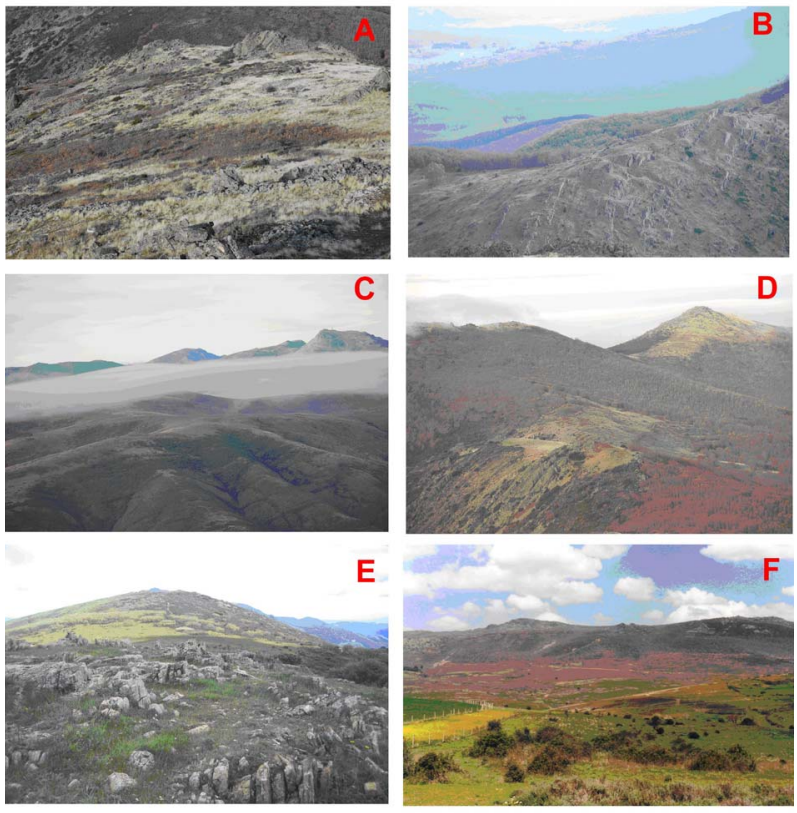

Figure 9. Saw Landscapes: Summits of quartzites with structures of periglacial (snow cover) in high areas of the hillside (A). Outstanding morphologic intensity of crest quartzites whose structural lithological alignments attract visual attention (B). Summits and crests in Las Quilamas, with arboreal and sub-shrubby formations, where the incisions of the water courses are striking (C). Summits where hills and crests alternate, defining lines on the horizon. Wooded and different zones of shrubs are differentiated (D). Limestones hills with alignments due to karstification (E). Sandstones hills conferring sinuosity to the area, with natural and anthropic (pastures and crops) forms. The landscape is reticulated by human activity (F).

lorfulness and beauty.

The quartzite outcrops at the top have generated highly vertical rocky headlands of landscape interest. These landscapes have a strong lithostructural component, although they tend to be located in rather inaccessible sites but with good visibility, and are elements of great singularity.

The 1.C.FD unit corresponds to summits of slate with scrubland and is found on the summits and ridges of Tamames (Figure 9(B)). They are present as gentler and more rounded morphologies, attracting less attention than the previous unit (Figure 9(B)) Unit 1.D.FD corresponds to limestone ridges and summits with scrub, also representative of some sectors of the Quilamas natural park (Figures 9(D) and (E)). The 1.E.FA. PaCyD unit is located in zones of hills and hills on sandstones, of low altitude or close to escarpments, where there are very well developed pastures and/or crops, as occurs with the vicinities of Serradilla del Arroyo, Serradilla del Llano (Figure 9(F)) and Tenebrón.

Hillside landscapes (2.A.FA.Pa.CB/2.C.FA.FD land- 
scape units). These form transition zones between the highest sectors-summits, ridges and hills-and the lowest sectors: river valleys that are more or less steepsided and alluvial plains. These sectors exhibit considerable erosive and depositional dynamics.

They feature singular granitic morphologies in which there are important megaforms and microforms, together with periglacial structures (striated surfaces) and arranged in angular blocks. There are also fluvial-torrent shapes. In the granitic zone there are complex forms with diffuse borders and a coarse texture with little contrast.

The very steep-sided slopes features scree and a texture ordered by the disposition of arboreal groups, with defined edges and they are three-dimensional in shape with a distance effect that is marked by the extent of the hillside. The gentler slopes display three-dimensional forms, lines with defined edges, an ordered texture and offer a panoramic space.

Unit 2.A.FA.Pa.CyB corresponds to landscapes of granitic hillsides with arboreal formations and dispersed pastures and croplands, as may be seen at San Miguel de Valero, San Esteban de la Sierra... In some granitic sectors, on the hillsides it is possible to observe characteristic forms of this type of lithology, such as granite boulders, hanging boulders, indentations, mounds and tafoni, mixed with mixed forms, although these cannot be differentiated since on the terrain they are not well visible since they are integrated in mosaics of plant formations in groups or are not contrasted because they are close to water courses in fitted valleys and outstandingly steep fluvial-torrent landscapes, as is the case of the River Alagón during its passage through San Esteban de la Sierra and San Miguel de Valero (Figure 10(A)).

The 2.C.FA.FD unit includes hillsides on slates and schists with trees at the bottom and colluvials and shrub on the medium-high part. This unit is seen to the $\mathrm{N}$ of Tamames, in the Honfría sector at Linares de Riofrío, and in the valleys of Las Batuecas (Figure 10(B)). In some sectors these hillsides show shrubby and/or subshrubby formations, such as in the Quilamas, with steeply sloped sides. The hillsides exposed to shade show greater diversity, with shrubs on the sides of paths and covers of broom, thyme, lavender and an abundant array of herbaceous species. Where there are mixtures of arboreal and shrubby-sub-shrubby formations, these units stand out from the substrate, as occurs in the neighborhood of Guadapero and some sectors within La Bastida district. On the lower parts of the hillsides, there are certain plant formations that are dominant in the perceptual environment, either due to their variety, structure or their plant density. Examples are the well conserved forests of oak, chestnut and pine, together with the sectors featuring heather on the upper parts of the hills, clearly differentiating the altitudinal structuring of the
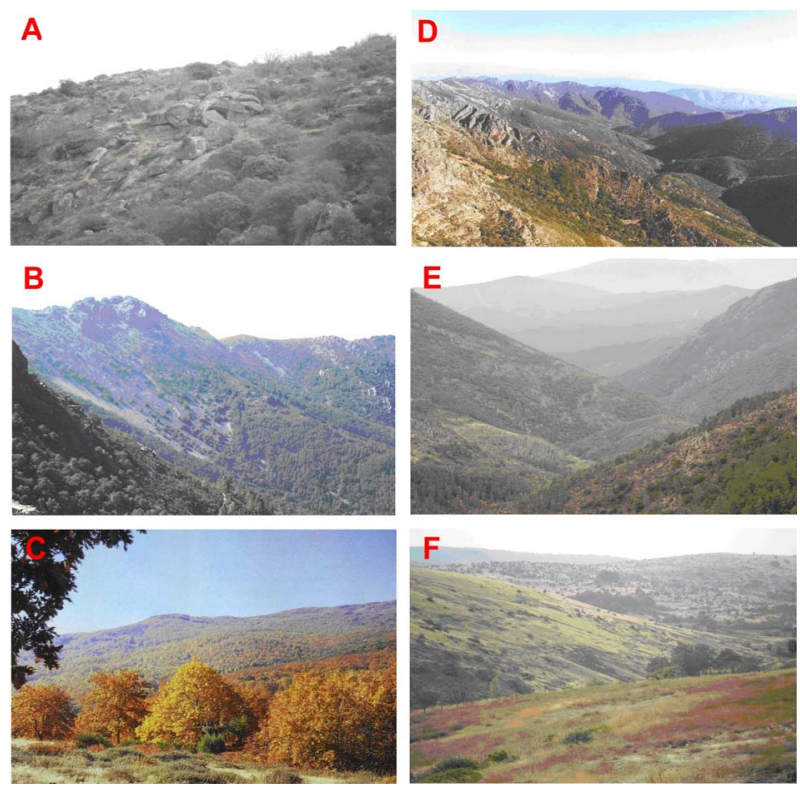

Figure 10. Hillside Landscapes: Hillsides with a granitic morphology, developed due to the alignment of fractures and cracks, with dispersed arboreal vegetation (A). Landscape showing quartzite crests without vegetation, with steeply sloped screes on the high part of the hillside, and with less dense arboreal forest owing to the lack of soil at the (B). Hillsides in Las Quilamas with colour contrasts in stands of chestnut-trees and oaks, with holm-oaks, oaks and dispersed pines. Highly contrasted arboreal formations and two-dimensional forms (C). Sinuosity of the traces followed by the fluvial network; reliefs fitted in the Las Batuecas valley(D). Symmetric valley of the river Francia, fitted and two-dimensional forms. Miranda del Castañar (E). Valley fitted in a substratum of gray slates and light coloured pastures of The Bastida.

arboreal and shrubby-subshrubby formations, as is the case of the slopes of the Quilamas (Figure 10(C)).

Landscapes of fitted valleys (3.A.FA.FD, 3.C.FM. $\mathrm{PaCyB}$ landscape units). The fitted valleys are sectors where the relief is of special importance, creating particular landscapes of great scenic value and a high degree of natural preservation. They are enclosed landscapes, where the visual limits are close to the point of observation owing to the existence of steep walls that act as visual barriers, closing off the scenic view. These landscapes are seen in the interior valleys of the Batuecas and the Quilamas, which have undergone frequent gravitational events such as rocks slides and falls. There are two landscape units represented in the fitted valleys, although they are the most spatially extensive ones and hence important, above all in the S and SE part of the study zone.

The first is the 3. A.FA.FD unit, which is formed by river valleys fitted in granites with erosive surfaces and featuring dispersed trees and bushes (Figure 10(D)). On the hillsides, there are rocky outcrops; these depend on 
the depth of the soil, above all in sectors with resistant granitic bedrock, allowing arboreal formations of oaks and holm-oaks, even in the surrounding of areas with fruit-trees, such as in Valero and San Esteban de la Sierra. The 3.C.FM.PaCyB unit represents valleys fitted in slates, with groups of trees, bushes and disperse cropfields. These are river valley sectors with an important tree density, associated with riparian forest. Important examples are the riverside forests found in the valley of Las Batuecas (Figure 10(E)). In general, the valleys associated with the saws of Las Batuecas-Sierra de Francia and Quilamas show a considerable visual barrier, with V-shaped morphologies and narrow vistas that increase the perception of the surrounding intrinsic landscape. The basin vistas are lengthened owing to the space allowed by the course of the rivers (Figure 10(F)). Also, differences in level indicate their young age, which is highlighted by specific geomorphological characteristics: rapids, scoured bottoms with pits and cascades, such as that found in the valley of Las Batuecas.

Scarp landscapes (5.C.E.FA.PaCyB Landscape Units). These correspond to sectors with scarps over slates and sandstones and conglomerates, with disperse trees and pastures. This type is geometric in shape, with defined edges, a coarse texture and considerable contrast. The scale shows a noteworthy effect of site and is highly attention-drawing. This unit is outstanding in the case of the river escarpments, such as the linear trace of the escarpment that runs from El Maillo to Aldehuela de Yeltes (Figure 11(A)), which has generated an asymmetric valley through retraction of the southern margin coinciding with the scarp. Additionally, in the western zone of the sector there are scarps on sandstones that have govern the morphology of the landscape, as is the case of the tectonic escarpment of the $\mathrm{W}$ sector.

Surface landscapes (4.G.PaCyB Landscape Unit). These include the sectors with more or less extended terrains that form the deposit-filled, erosion, pediment and piedmont surfaces. These surfaces are very broad and are important in the $\mathrm{N}$ sector of the study area. They are also are somewhat more disperse between both sierras (Francia and Quilama), where the morphology is sometimes governed by geomorphological factors, such as at Nava de Francia. They display two-dimensional forms, with silhouetted lines, a fine texture and high contrast. The scale shows a distance effect owing to the broadness of the unit and a panoramic space. The unit found in this type of landscape is 4.G.PaCyB, which forms piedmont surfaces over outcrops of conglomerates and sandstones with crops. Sometimes these surfaces are associated with holm-oak and oak forests, located between villages, and on eroded or sediment-filled surfaces. This unit is distributed along the zone of confluence between the lower parts of hillsides and surfaces,
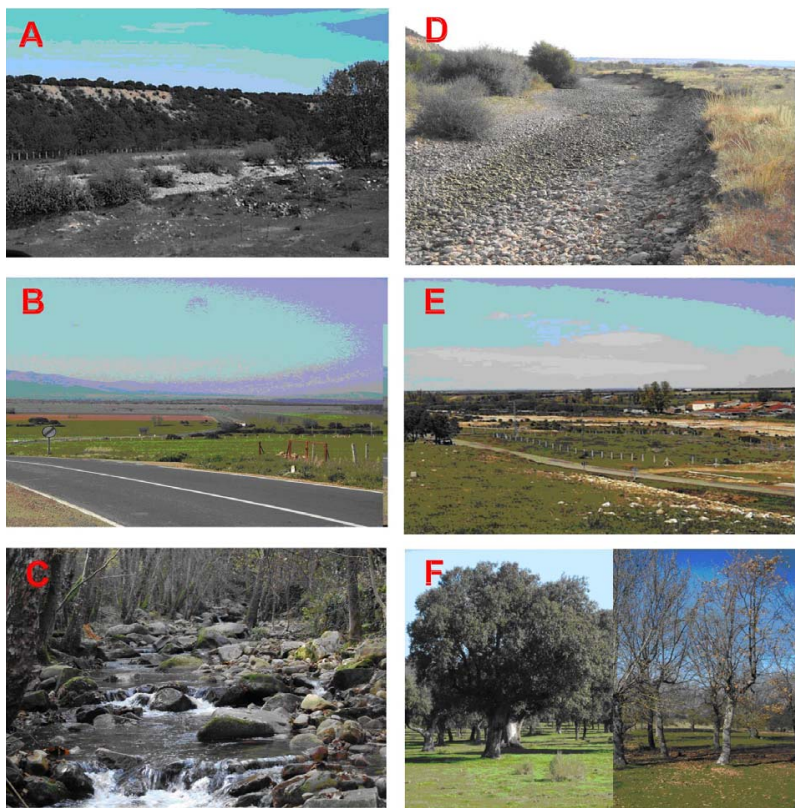

Figure 11. Landscapes of the fluvial escarpment between El Maillo-Aldehuela de Yeltes. The lithology is well visible and there is a tract of associated vegetation of riparian galleries (A). Surface landscapes: flat surfaces of foothills with pastures (B). Landscapes of terraces and valley floors: alluvial of the river Batuecas inside the Las Batuecas valley with dense bank vegetation (C), alluvial riverbed with a coarse texture of the river Yeltes, with defined edges and erosive forms of fluvial margin. Aldehuela de Yeltes (D), riverbed, with human activities intercalated with the vegetation of black poplars at Morasverdes; and fluvial terraces with arboreal formations of holm-oaks (left) and oaks (right).

showing diffuse borders owing to the presence of shrubby-subshrubby plant formations. These formations are found in the study zone both at the edges of anthropic surfaces in the $\mathrm{W}$ sector and close to the mid-stretches of rivers in the central sector. In some sectors, the presence of dehesa environments for traditional sustained use is very common, where the sclerophyllous forest has been cleaned of bushes, the mature elements of the forest coexisting with semi-natural communities (pastures. Crops and livestock) in a sustainable relationship (Figure 11(B)).

Terrace and valley floor landscapes (6.F.FA.FD. PaCyB Landscape Unit), generally with disperse groups of trees and crops. They integrate river course and/or valley sectors where there is a mixture of arboreal formations with shrubby and subshrubby mosaics. These units are associated with braided river channels. This landscape is organized around the fluvial axes harboring most villages are located Morasverdes, Tenebron and Dios le Guarde and the surfaces have been converted into irrigated lands. These landscapes are linked to the presence of surface water, which allows the development of river bank vegetation in its surroundings. 
There is a predominance of biotic elements (riverside vegetation) and abiotic ones (gravels from river beds) (Figure 11(C); Figure 11(D)) Anthropic elements are also seen, and attract much visual attention, above all in the cropland surfaces and, to a lesser extent, in the villages and highways. The relief here becomes less important since its forms are not very prominent, where some of the biotic elements are relegated to a lesser position due to transformation through human action. It is sometimes possible to fairly large observe sectors with open tree formations and, noting from inside the adjacent scenic components, as is the case of the felled forests of oak, chestnut and pines present on the lower slopes of the Quilama and Francia saws, extending to the river terraces. At the Quilamas stream there is a series of stepped surfaces on the summit zones, where the relief reflects strong energy in the encasement of the river bed. These slopes support a rich and varied vegetation of arboreal formations on the low and medium parts and shrubby formations higher up. Overall it is a zone of great of great natural attraction where biotic and abiotic elements predominate and the anthropic elements have been relegated to second place. This unit has sectors with narrow vistas, which increase their perception, with deep visual extensions, medium textures, showing sharp visual changes when they are crossed by roads, agricultural tracks, etc. The agricultural activities have generated territorial plots with structures (walls, fences, banks, orchards...) that have afforded a reticulated landscape, $n$ which the anthropic component predominates over the natural ones, the remnants of forests, testimony to period of greater development, are very singular. In some sectors there are forest repopulations that draw attention to mixed formations containing species of great singularity. There are also sectors with terraces in which human activity has been so intense, that the initial natural assets have been replaced by features deriving from anthropic activity (Figure 11(E)).

An example of these landscapes are all the sectors of pastures and croplands in the neighborhoods of villages, where traditional sustainable use of the land has left an imprint of human activities, the remains of the traditional ecosystem (deciduous and sclerophyllous forests) coexisting with seminatural communities (meadows, croplands...) (Figure 11(F)). In spring, these meadows of vivacious species and pasturelands are highly coloured and together with the presence of the seasonal livestock they generate sectors with an important visual effect. The same is the case for orchards and croplands owing to the variety in the ordering of their distribution, as well as the presence of people and machinery exploiting such areas. These sectors have traditional and cultural value. Finally, it should be noted that the large number of ponds distributed throughout these sectors, many of them artificial, have generated added visual value since they are associated with vegetation and the fauna.

\section{Results}

In the landscape analysis reported here we have established the landscape units of the protected natural parks by indirect methods, performing the description and assessment of the mapping of homogeneous and natural or environmental units, bearing in mind their natural components. Using direct methods we determined the visual characteristics and perceptual factors of the most representative units of the study zone in field studies, using three-dimensional models and photos taken from and air and in the field to appreciate the spatial distribution and relevance of the different parameters. This analysis defines the landscape units, which divide the territory into homogeneous sectors or extensive irregular units, depending on the structure, functionality and visual characteristics of the natural components. The geomorphological component has greater weight than the lithological one and the vegetation, since the spatial configuration of the relief predominates in the landscape. Based on this study some important conclusions are observed:

1) The landscape units in the summit sectors show the following relevant features: summit sector with no vegetation or with shrubs covered by colluvials, especially screes, which stand out in the landscape owing to their disposition and colour. Likewise, note should be taken of the hill and hillock sectors with arboreal formations and, to a lesser extent, pasturelands, croplands and fallow land, in the $\mathrm{W}$ sector.

2) The hillsides afford highly representative landscape units in the centre of the natural parks of Las Batuecas-Sierra de Francia and in the NE sector of the study zone, with a predominance in the rest of the natural park of large patches of shrubby-subshrubby formations.

3) The fitted valley sectors are distributed within the Quilamas natural park and the central and southern parts of the Batuecas-Sierra de Francia, with a predominance of shrubby and subshrubby formations in the inter-range sectors, followed by mixed formations in zones adjacent to the previous ones but of less extent in the $\mathrm{E}$ and SE zone. Less spatial representation is seen for the units with arboreal formations, which are distributed in the S sector surrounding river valleys.

4) The unit of surfaces with crops is distributed across the periphery of the natural parks being limited to the $\mathrm{N}$ and $\mathrm{W}$ sectors, with a predominance of croplands and pasturelands on the sediment-filled surfaces, N sector, and on erosive surfaces: $W$ sector.

5) The escarpment unit over slates and sandstones with trees and pasturelands stands out on the right bank of the river Yeltes, displacing and retracting the fluvial escarpment that runs from El Maillo to Aldehuela de Yeltes, 
and the tectonic escarpment to the NW of the study zone.

6) Finally, the terrace and valley floor unit, mainly associated with the river courses in the $\mathrm{N}$ of the study zone, features arboreal formations in the $\mathrm{N}$ and $\mathrm{E}$ sectors, and on the valley floors there is a predominance of riverside arboreal formations and/or forest repopulations.

7) The treatment used here considers landscape not only as an aesthetic element but also as something "live" that evolves over time due to the presence of natural phenomena, a dynamic landscape, and the anthropic involvement that has increased or decreased this rate of evolution. Regarding environmental planning, study of the visible landscape should be based on maps that should be of use in land planning and management. Accordingly, the landscape assessment made here has a dual aim: on one hand, the presence and distribution of the landscape components (forms and slopes of the terrain, the presence of vegetation, land use...) and, on the other, the absence of impacts that will degrade the natural environment (residues, infrastructures, noise...); that is, on one hand we analyze the "total landscape" that identifies the landscape with the environment on the basis of the thematic components of the territory. We emphasize the geomorphological factor since this imprints a spatial dominance of forms and processes through the disposition of the relief and its active processes, the lithological coloring and the distribution of the vegetation according to height. On the other, we address the "visual landscape", where we assess the natural environment on the basis of aesthetic or perceptual criteria by modeling the terrain in 3D, thus allowing a more efficient spatial analysis. The first approach provides systematic information about the territory, whereas the second one identifies what the observer is able to perceive in that territory.

8) These landscape units offer a causal interpretation of the forms of the terrain and of the changing elements (a natural dynamic landscape) and their structure and spatial relationships.

9) The identification and characterization of the different landscape units has allowed us to establish the compatible and incompatible uses, attending to criteria of assessment, protection, management and ordering, always from the perspective of the sustainable development of each unit. The maintenance of the functionality of these natural parks through conservation, recovery and landscape integration of the underlying geological, biotic and socioeconomic system is a guarantee of landscape viability.

\section{Acknowledgements}

Projects CGL2012-33430/BTE and

CGL2012-37581-CO2-01.

\section{REFERENCES}

[1] F. D. Pineda, "Terrestrial Ecosystems Adyacent to Larg Reservoirs,” International Committee on Large Dams, XI Congress, Paris, 1973.

[2] M. Dunn, "Landscape Evaluation Techniques: An Appraisal and Review of the Literature," Centre of Urban and Regional Studies, Birminghan, 1974.

[3] W. Nohl, "Sustainable Landscape Use and Aesthetic Perception-Preliminary Reflections on Future Landscape Aesthetics," Landscape and Urban Planning, Vol. 54, No. 1-4, 2001, pp. 223-237. doi:10.1016/S0169-2046(01)00138-4

[4] R. De Groot, "Function-Analysis and Valuation as a Tool to Assess Land Use Conflicts in Planning for Sustainable, Multi-Functional Landscapes," Landscape and Urban Planning, Vol. 75, No. 3-4, 2006, pp. 175-186. doi:10.1016/j.landurbplan.2005.02.016

[5] K. Soinia, H. Vaaralab and E. Poutaa, “Residents' Sense of Place and Landscape Perceptions at the Rural-Urban Interface," Landscape and Urban Planning, Vol. 104, No. 1, 2012, pp. 124-134. doi:10.1016/j.landurbplan.2011.10.002

[6] A. García-Quintana, J. F. Martín-Duque, J. A. GonzálezMartín, J. F. García-Hidalgo, J. Pedraza, P. Herranz, R. Rincón and H. Estévez, "Geology and Rural Landscapes in Central Spain (Guadalajara, Castilla-la Mancha),” Environmental Geology, Vol. 47, No. 6, 2005, pp. 782-794.

[7] J. A. Soria and F. G. Quiroga, “Análisis y Valoración del Paisaje en las Sierras de la Paramera y la Serrota (Ávila),” M + A Revista Electrónica de Medio Ambiente, No. 1, 2006, pp. 97-119.

[8] A. M. Martínez-Graña, J. L.Goy and C. Zazo, "Natural Heritage Mapping of the Batuecas-Sierra de Francia and Quilamas Nature Parks (SW Salamanca, Spain),” Journal of Map, Vol. 7, No. 1, 2011, pp. 600-613.

[9] R. Beunen and P. Opdam, "When Landscape Planning Becomes Landscape Governance, What Happens to the Science?” Landscape and Urban Planning, Vol. 100, No. 4, 2011, pp. 324-326. doi:10.1016/j.landurbplan.2011.01.018

[10] B. A. Bryan, "Physical Environmental Modeling, Visualization and Query for Supporting Landscape Planning Decisions," Landscape and Urban Planning, Vol. 65, No. 4, 2003, pp. 237-259. doi:10.1016/S0169-2046(03)00059-8

[11] C. He, J. Tianc, P. Shia and D. Hud, "Simulation of the Spatial Stress Due to Urban Expansion on the Wetlands in Beijing, China Using a GIS-Based Assessment Model," Landscape and Urban Planning, Vol. 101, No. 3, 2011, pp. 269-277. doi:10.1016/j.landurbplan.2011.02.032

[12] F. Gobattonia, R. Pelorossoa, G. Laurob, A. Leonea and R. A. Monacoc, "Procedure for Mathematical Analysis of Landscape Evolution and Equilibrium Scenarios Assessment," Landscape and Urban Planning, Vol. 103, No. 3-4, 2011, pp. 289-302. doi:10.1016/j.landurbplan.2011.08.011

[13] European Union, “Relativa a la Evaluación de las Reper- 
cusiones de Determinados Proyectos Públicos y Privados Sobre el Medio Ambiente," European Union, Luxembourg, 1985.

[14] Pacific Northwest Christmas Tree Association, "Plan Nacional de Cartografía Temática Ambiental. Análisis y Desarrollo Ministerio de Medio Ambiente,” PNCTA Documento Técnico, Madrid, 1996.

[15] Bank of England, "Instrumento de Ratificación del Convenio Europeo del Paisaje,” 2008. http://www.juntadeandalucia.es/obraspublicasyvivieda/est atcas/sites/consejeria/areas/ordenacion/documentos/Conv encionEuropeadelPaisaje.pdf

[16] I. O. Pastor, S. M. Quintana and E. O. Pérez, "El Paisaje como Elemento en la Evaluación Ambiental Estratégica de Planes de Infraestructuras. Cartografía de la Calidad del Paisaje de España,” I Congreso Paisaje e Infraestructuras, Sevilla, 2006.

[17] I. O. Pastor, M. A. C. Martínez, A. E. Canalejo and P. E. Mariño, "Landscape Evaluation: Comparison of Evaluation Methods in a Region of Spain,” Journal of Environmental Management Vol. 85, No. 1, 2007, pp. 204-214. doi:10.1016/j.jenvman.2006.09.018

[18] Convenio Europeo, "Recomendación del Comité de Ministros a los Estados Miembro Sobre las Orientaciones para la Aplicación del Convenio Europeo del Paisaje,” Convenio Europeo, London, 2008.

[19] Diari Oficial de la Generalitat de Catalunya, "De Protección, Gestión y Ordenación dl Paisaje, y Se Regulan los Estudios e Informes de Impacto e Integración Paisajística,” Diario Oficial de la Generalitat de Catanlunya,
Sevilla, 2006.

[20] F. G. Bernáldez, “Ecología y Paisaje,” Blume, Madrid. 1981.

[21] Y. M. Ayad, "Remote Sensing and GIS in Modeling Visual Landscape Change: A Case Study of the Northwestern Arid Coast of Egypt," Landscape and Urban Planning, Vol. 73, No. 4, 2005, pp. 307-325. doi:10.1016/j.landurbplan.2004.08.002

[22] Y. Liu, X. Lv, X. Qin, H. Guo, Y. Yu, J. Wang and G. Mao, "An Integrated GIS-Based Analysis System for Land-Use Management of Lake Areas in Urban Fringe," Landscape and Urban Planning, Vol. 82, No. 4, 2007, pp. 233-246. doi:10.1016/j.landurbplan.2007.02.012

[23] M. G. Aguiló, "Metodológica para la Elaboración de Estudios del Medio Físico," Secretaria General del Ministerio de Obras Públicas y Transportes, Madrid, 2000.

[24] P. Ghadirian and I. D. Bishop, "Integration of Augmented Reality and GIS: A New Approach to Realistic Landscape Visualisation,” Landscape and Urban Planning, Vol. 86, No. 3-4, 2008, pp. 226-232. doi:10.1016/j.landurbplan.2008.03.004

[25] R. G. Echevarría, "La Fotografía Elemento para el Análisis y la Simulación del Paisaje Forestal,” Tesis Doctoral, Universidad Autónoma de Madrid, Madrid, 2000,

[26] J. F. Palmer and L. J. Roos-Klein, "Evaluating Visible Spatial Diversity in the Landscape," Landscape and Urban Planning, Vol. 43, No. 1-3, 1998, pp. 65-78. doi:10.1016/S0169-2046(98)00077-2 